\title{
ESTUDIO DE CASO AGUARDIENTE: APLICACIÓN DEL MODELO DE INFOCONOCIMIENTO*
}

\author{
AGUARDIENTE CASE STUDY: APPLICATION OF THE \\ INFOKNOWLEDGE MODEL
}

\author{
ESTUDO DE CASO AGUARDIENTE: APLICACÃO DO MODELO DE \\ INFO-CONHECIMENTO
}

\author{
ÉTUDE DE CAS AGUARDIENTE: APPLICATION DU MODELE \\ D,INFOCONNAISSANCE
}

\author{
FERNANDO SALCEDO VITOLA ${ }^{\dagger}$ \\ JENNIFFER CAROLINA RIVEROS MARENTES ${ }^{\ddagger}$ \\ MARISLEIDY ALBA CABAÑAS \\ NOÉ VELÁZQUEZ ESPINOZAఠ
}

Fecha de recepción: 6 de julio de 2020

Fecha de aprobación: 10 de octubre de 2020

* Artículo de investigación. Grupo de investigación en Sistema de Información y Control Organizacional. Facultad de Contaduría Pública de la Universidad Externado de Colombia. Consultoría sobre gestión del conocimiento en empresas productoras.

† Ingeniero electrónico, Universidad Santo Tomás, Bogotá, Colombia; especialista en Gerencia de proyectos de Ingeniería, Universidad EAN, Bogotá, Colombia; magíster en Gerencia Estratégica de Tecnologías de la Información, Universidad Externado de Colombia, Bogotá; gerente digital de Proyectos, HITSS Colombia, Bogotá. fernando. salcedo01@est.vexternado.edu.co - https://orcid.org/0000-0003-091 1-5544

‡ Administradora de empresas, Universidad de La Salle, Bogotá, Colombia; magíster en Gerencia Estratégica de Tecnologías de la Información, Universidad Externado de Colombia, Bogotá; gestor de proyectos y calidad de la información Bancamía, Bogotá. jenniffer.riveros@est.vexternado.edu.co - https://orcid.org/0000-0002$\underline{1065-0336}$

§ Ingeniera informática, magíster en Gestión de Información; PhD en Ciencias Económicas, Universidad de La Habana, Cuba; coordinadora de investigación de la Facultad de Contaduría, Universidad Externado de Colombia. Grupo de investigación en Sistema de Información y Control Organizacional. marisleidy.alba@uexternado. edu.co - htps: / / orcid.org/0000-000 1-6935-6097

$\varnothing$ Licenciado en Economía; maestría en administración de negocios; maestría en Finanzas corporativas; doctor en Ciencias de la Administración, Universidad del Valle de Atemajac (UNIVA), León, México; director, Centro de gestión de información y finanzas, Facultad de Administración de Empresas, Universidad Externado de Colombia..noe.velasquez@uexternado.edu.co - https://orcid.org/0000-0002$\underline{7768-2279}$ 


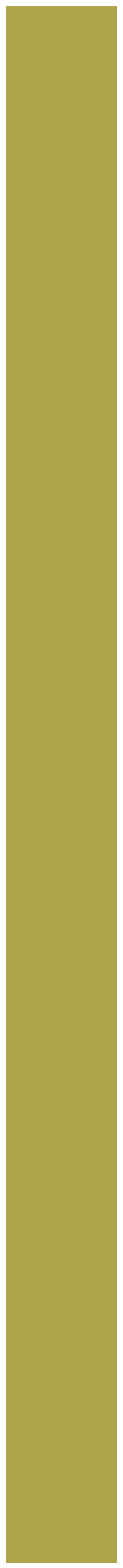

En tiempos de cambios constantes y acelerados el entorno actual empresarial se caracteriza por la necesidad de introducir el conocimiento en las actividades que se desarrollan. Las organizaciones reconocen que los factores de conocimiento tienen un impacto significativo o valor agregado en el resultado de las empresas. Es por esta necesidad detectada por lo que se presenta un estudio en la producción de aguardiente bajo la metodología de caso, a partir de presentar un marco conceptual, la dinámica de investigación y el escrutinio de la literatura. Esto permite aportar una teoría como propuesta de solución al uso, transferencia y conservación del conocimiento, reconocimiento de flujos de información, políticas de almacenamiento y difusión para la producción de aguardiente.

La propuesta permite validar la teoría del infoconocimiento e incorporar a la misma una nueva herramienta tecnológica que garantiza el tratamiento integral de las funcionalidades previstas en el modelo de infoconocimiento; con esto el proceso de aguardiente garantiza tratamiento anticipado, la minería de datos, la gestión de contenidos, la monitorización del proceso, las notificaciones y el funcionamiento de la red de expertos.

\section{PALABRAS CLAVE:}

gestión de contenidos, gestión de proceso, herramienta tecnológica, minería de datos, monitorización del proceso, notificaciones, red de expertos.

In times of constant and accelerated changes, the current business environment is characterized by the need to introduce knowledge in the activities developed. Organizations recognize that knowledge factors have a significant impact or added value on business performance. It is because of this need that a study on the production of spirits (aguardiente) under the case study methodology is presented in this article, by presenting a conceptual framework, research dynamics and literature review. This allows providing a theory as a proposed solution to the use, transfer and conservation of knowledge, recognition of information flows, storage and dissemination policies for the production of spirits. 
The proposal allows validating the theory of infoknowledge and incorporating to it a new technological tool that guarantees the integral treatment of the functionalities foreseen in the infoknowledge model, with this, the process of spirits ensures advance processing, data mining, content management, process monitoring, notifications and the operation of the network of experts.

Keywords: content management; data mining; expert network; notifications; process management, process monitoring; technology tolos.

JEL classification: D83, M13, M21, O31.

RESUMO

Em tempos de mudança constante e acelerada, o actual ambiente empresarial é caracterizado pela necessidade de introduzir conhecimentos nas actividades que são desenvolvidas. As organizações reconhecem que os factores de conhecimento têm um impacto significativo ou um valor acrescentado no resultado das empresas. É devido a esta necessidade detectada que é apresentado um estudo na produção de aguardente sob a metodologia do caso, a partir da apresentação de um quadro conceptual, da dinâmica da investigação e do escrutínio da literatura. Isto permite fornecer uma teoria como solução proposta para a utilização, transferência e conservação do conhecimento, reconhecimento dos fluxos de informação, políticas de armazenamento e disseminação para a produção de aguardiente.

A proposta permite validar a teoria do infoknowledge e incorporar-lhe uma nova ferramenta tecnológica que garante o tratamento integral das funcionalidades previstas no modelo de infoknowledge; com isto o processo de aguardiente garante o tratamento antecipado, a extracção de dados, a gestão de conteúdos, a monitorização do processo, as notificações e o funcionamento da rede de peritos.

Palavras-chave: ferramenta tecnológica, gestão de conteúdos, gestão de processos, mineração de dados, monitorização de processos, notificações, rede de peritos.

Classificação JEL: D83, M13, M21, O31.

\section{RESUME}

En période de changement constant et accéléré, l'environnement actuel des entreprises se caractérise par la nécessité d'introduire des connaissances dans les activités qui sont développées. Les organisations reconnaissent que les facteurs de connaissance ont un impact significatif ou une valeur ajoutée dans le résultat des entreprises. C'est en raison de ce besoin 


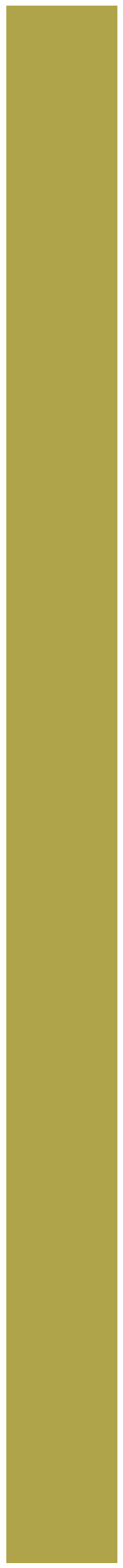

détecté que l'on présente une étude de la production de aguardiente sous la méthodologie des cas, à partir de la présentation d'un cadre conceptuel, de la dynamique de la recherche et de l'examen de la littérature. Cela permet de fournir une théorie comme solution proposée à l'utilisation, au transfert et à la conservation des connaissances, à la reconnaissance des flux d'information, aux politiques de stockage et de diffusion pour la production de aguardiente.

La proposition permet de valider la théorie de l'infoconnaissance et d'y incorporer un nouvel outil technologique qui garantit le traitement intégral des fonctionnalités prévues dans le modèle d'infoconnaissance; avec cela le processus d'aguardiente garantit le traitement anticipé, l'exploration de données, la gestion du contenu, le suivi du processus, les notifications et le fonctionnement du réseau d'experts.

Mots clés: exploration de données; gestion de contenu; gestion de processus; notifications; outil technologique; réseau d'experts; surveillance de processus.

Classification JEL: D83, M13, M21, O31.

\section{INTRODUCCIÓN}

La necesidad de estudiar desde la gestión del conocimiento un caso en el contexto colombiano dedicado a la producción de aguardiente es el principal objetivo de esta investigación. Los motivos principales que se evidencian son la fuga de conocimiento tácito, el limitado uso, transferencia y conservación del conocimiento, la ausencia de flujos de información y de políticas de almacenamiento y difusión.

Para ello se selecciona el diseño de investigación de casos (Yin, 1981 ) y los criterios clásicos de calidad aceptados para los estudios positivistas ${ }^{1}$ (validez de constructo, validez interna, validez externa y fiabilidad) (Yin, 1984; Denzin \& Lincoln, 1994; Lincoln \& Guba, 1985; Robson, 1993). Así como los pasos para el desarrollo de estudios de casos propuestos por Cepeda \& Carrión (2006): marco conceptual, dinámica de investigación, escrutinio de la literatura para generar teoría (figura 1).

Para lograr el estudio de casos se define como problema de investigación, ¿̇cómo lograr uso, transferencia y conservación del

1 Atendiendo a las características de los estudios de caso (Benbasat et al., 1987). 
conocimiento, reconocimiento de flujos de información, políticas de almacenamiento y difusión en la producción de aguardiente? Considerado como la pretensión fundamental la de validar y aportar a la teoría de infoconocimiento (desde su modelo de gestión) en la producción de aguardiente, se asume como planteamiento hipotético la idea de que el modelo de gestión del infonocimiento contribuye al uso, transferencia y conservación del conocimiento, reconocimiento de flujos de información, políticas de almacenamiento y difusión en la producción de aguardiente. Para ello las variables de estudio serán: uso, transferencia y conservación del conocimiento, reconocimiento de flujos de información, políticas de almacenamiento y difusión desde los modelos de gestión del conocimiento.

Figura 1. Dinámica de investigación en estudios de caso.

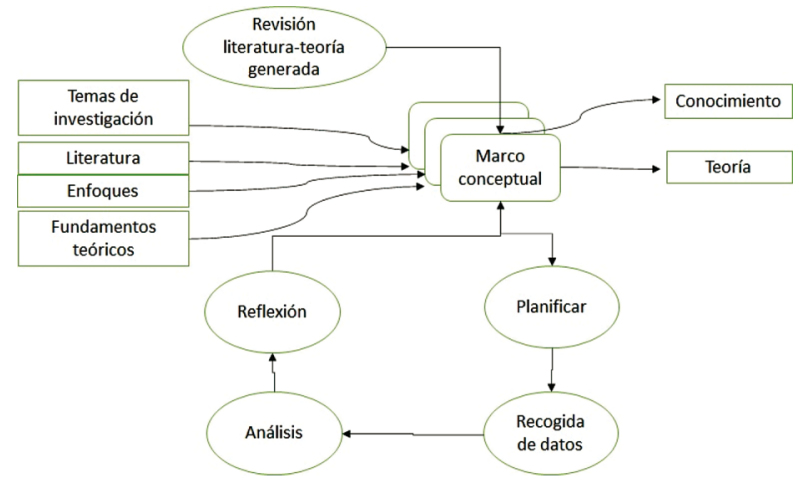

Fuente: adaptado de Cepeda Carrión (2006).

Para confirmar esta idea se presenta el desarrollo conceptual siguiendo la guía metodológica para la revisión de la literatura propuesta por Okoli \& Schabram (2010), en donde se evidencia la división en cuatro categorías: planeación, selección, extracción y ejecución. Dentro de estas etapas se puede observar: la identificación de autores, la selección de búsqueda de la literatura, así como la revisión de enfoques, la construcción del marco teórico y la aplicación de las herramientas tecnológicas que apoyan la gestión de la información y el conocimiento (figura 2).
Figura 2. Guía para el desarrollo de la revisión de literatura.

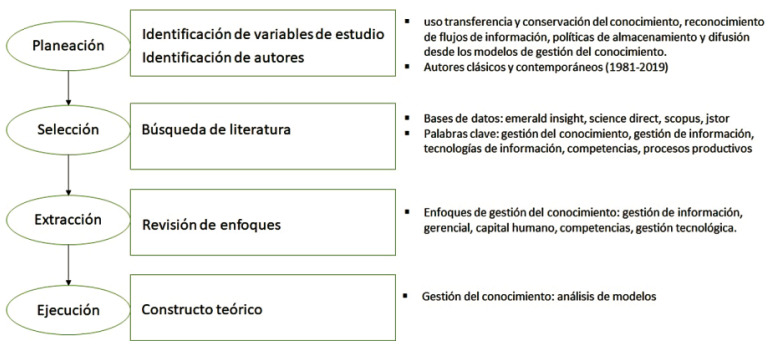

Fuente: Elaboración propia a partir de Okoli \& Schabram (2010).

En la presente investigación se pudo identificar una variedad de modelos de gestión del conocimiento: Alba (2013); Alba \& Herrera (2016); Andersen (1999); Arias-Pérez, TaveraMesias \& Castaño-Serna (2016); Arias \& Tavera (2015); Briceño Moreno \& Bernal Torres (2010); Choo (1995); Dataware Technologies Inc. (1998); González, Joaquí, \& Collazos (2009); Firestone (2001); Follador \& Gonzaga (2015); Franch, Herrera \& Losada (2011); Hedlund (1994); Kerschberg (2000); Kogut \& Zander (1992); Nonaka \& Takeuchi (1995); Oliveira, Pedron, Romão, \& Becker (2011); Romero \& Pascal (2011); Soto Balbón (2005); Sveiby (1997); Tejedor \& Aguirre, (1998); Wiig, (1993)g.. who knows what. Una revisión demuestra que los modelos más antiguos se concentraban en plantear el panorama a la luz de integrar variables en un esquema donde las opciones de materializarse estaban poco previstas. A lo largo de los años las investigaciones fueron integrando otras variables, entre ellas la tecnología de información; sin embargo, en la revisión de los modelos (anexo 1) no se evidenció integración entre modelos y soportes informáticos. Los soportes no articulan todas las demandas del modelo y surgen como soporte de algunas funciones. En cuanto a los soportes, estos carecen de enfoque activo de gestión y de transferencia de conocimientos. Las relaciones que se establecen son reactivas, como repositorios de conocimientos o bases de datos. La gestión no la realizan en tiempo real. 
Dentro de estos modelos resalta la concepción del infoconocimiento que articula la gestión de los procesos que se llevan a cabo en la cadena de suministro bajo el criterio del infoconocimiento, encargado de integrar los flujos de información y conocimiento entre los actores, sus experiencias, el aprendizaje y las competencias, a partir del desarrollo de un pensamiento en espiral como enfoque de proceso, creciente y sinérgico, que agrega valor y crea las bases para la innovación organizacional y de productos (Alba, 2016).

El modelo genera una espiral (infoconocimiento), la cual permite la determinación y organización de la información relevante mediante el filtrado, la disponibilidad de los contenidos, el almacenamiento de fuentes, la incorporación de juicios de valor en puntos clave de la cadena, aportados por la participación de expertos y personal involucrado, los que a su vez intervienen de manera creadora en la adquisición, la comunicación y la toma de decisiones.

\section{METODOLOGÍA}

\subsection{DINÁMICA DE INVESTIGACIÓN - PLANIFICAR}

Para este estudio, la dinámica de investigación reconoce las aportaciones de un proceso de consultoría con la participación de Salcedo y Riveros (2020), lo cual permite generar una discusión sobre los modelos de gestión del conocimiento y sus soportes tecnológicos para comprobar y aportar a la concepción del infoconocimiento. En este estudio se utiliza la investigación positivista del caso de estudio (Cepeda-Garrión, 2006) para validar el modelo de infoconocimiento e incorporar una nueva funcionalidad a esta concepción. La dinámica de este estudio obedece a la investigaciónacción, lo cual permite ir construyendo a lo largo del desarrollo del diagnóstico.

\subsubsection{Identificación del caso de estudio}

El caso de estudio que se presenta corresponde a la producción de aguardiente; dentro de este proceso se identifican los actores: cuatro (4) subgerencias y dos (2) oficinas asesoras, dentro de las cuales están: la subgerencia administrativa, subgerencia técnica, subgerencia comercial, subgerencia financiera, oficina de gestión contractual y la oficina asesora de planeación, las cuales hacen parte del contexto empresarial e interactúan entre sí con el fin de asegurar la producción del aguardiente; además se puede observar que existen otros agentes identificados como actores externos, los cuales son proveedores, clientes e instituciones; estos se caracterizan por influenciar el proceso desde las perspectivas exógenas a la fabricación pero que afectan en gran medida las decisiones y acciones que se ejecutan en la producción de aguardiente (Salcedo y Riveros, 2020) (figura 3).

Figura 3. Identificación de actores y sistemas de relaciones.

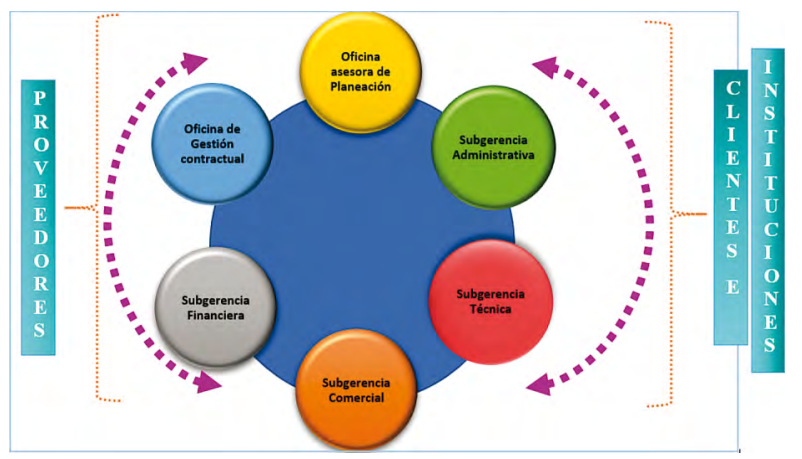

Fuente: Elaboración propia

Una vez identificados los actores a través de la entrevista personal (anexo 2), se verificó la existencia de un sistema de relaciones con las respectivas conexiones y sinergias operativas. Tal como se ilustra en la figura 4, existe una interrelación constante y necesaria entre los actores pertenecientes al sistema de relaciones entre los cuales fluye información (datos de entrada, procesamiento y salidal para obtener el producto final, el aguardiente. 
A partir de la figura 4, fase 2, se establece la selección del producto motivo de estudio, donde se analizó, mediante entrevista personal lanexo 2) y el análisis documental, la identificación del producto de aguardiente, ya que dentro de la producción representa 95\% del total de las ventas, por lo que en el mercado de licores constituye una importante fuente de ingresos.

Figura 4. Sistemas de relaciones en el proceso de producción de aguardiente.

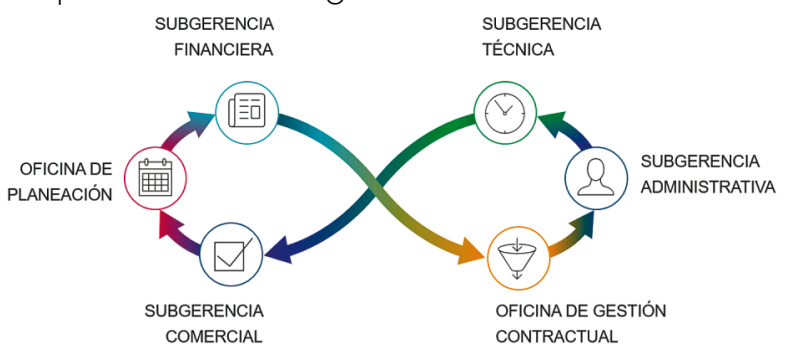

Fuente: Elaboración propia.
Para lograr comprender la estructura del proceso correspondiente a la producción del aguardiente, se construyó un diagrama de procesos que presenta la interacción entre los actores, sus procesos y su participación en la producción de aguardiente.

La figura 5 se construye a partir de la identificación de un flujo de procesos (no definido con anterioridad en el proceso productivol, el cual involucra a todas las etapas de la producción de aguardiente.

\subsubsection{Metodología de diagnóstico}

La metodología de diagnóstico seleccionada para analizar el proceso de producción de aguardiente es la planteada por Alba (2020); los criterios de selección para la metodología

Figura 5. Flujo de procesos de producción del aguardiente.

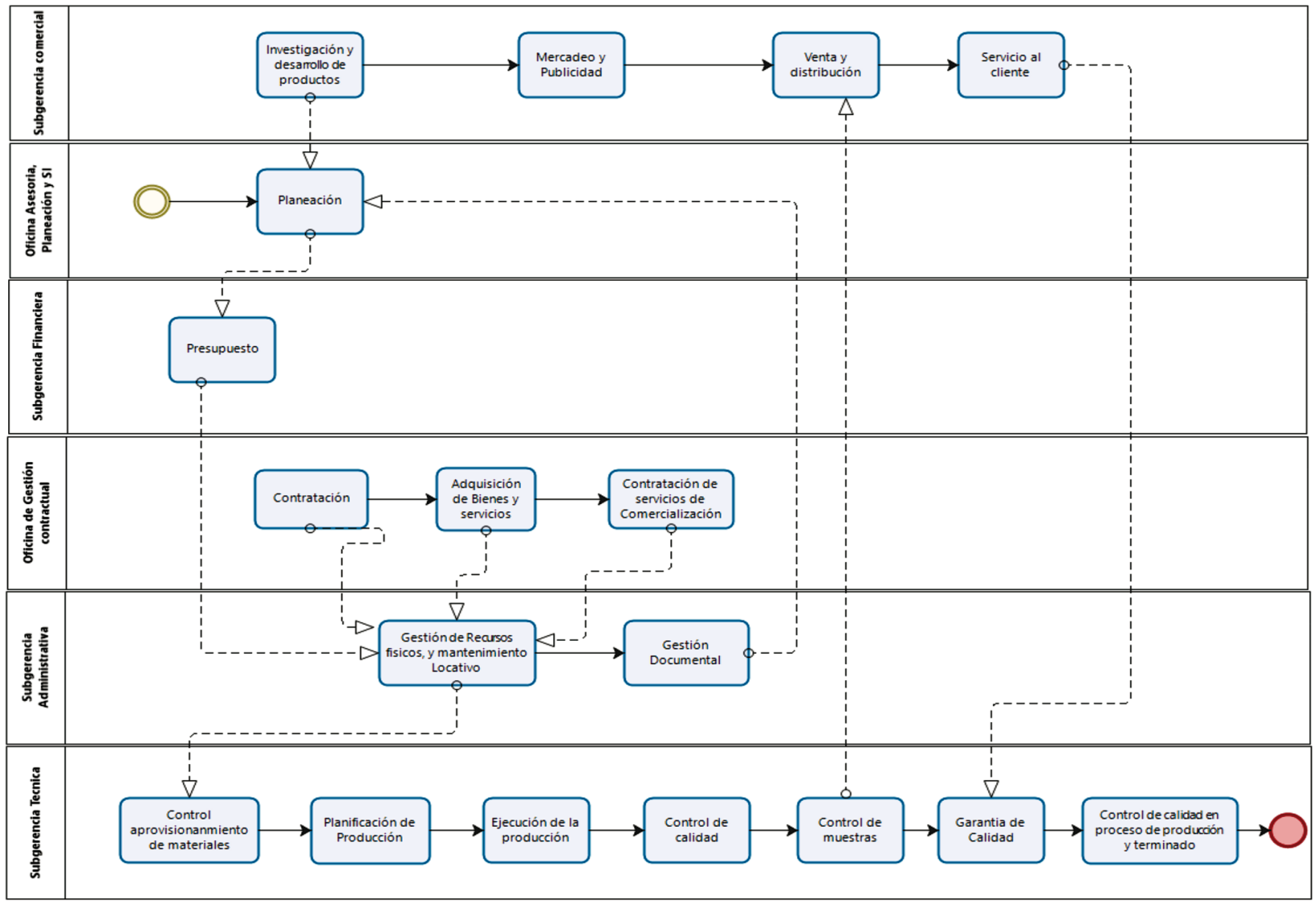

Fuente: Elaboración propia. 
fueron los analizados por Salcedo y Riveros (2020). Esta metodología permite flexibilidad en su aplicación, pudiendo ejecutarse en procesos productivos grandes o pequeños, y recoge todos los procesos de gestión de información, gestión del conocimiento y tecnologías de información. Esta metodología está compuesta por seis etapas y un conjunto de pasos en los que se logra realizar un diagnóstico integral que reconoce procesos, las ideas rectoras, las áreas de conocimiento, las competencias del personal; así como necesidades, informaciones y aplicaciones tecnológicas (figura 6). A continuación, se presenta algunos de los resultados obtenidos con la aplicación de esta metodología.

Figura 6. Metodología para el diagnóstico de la gestión de información, conocimiento y las tecnologías de información en el proceso de producción de aguardiente.

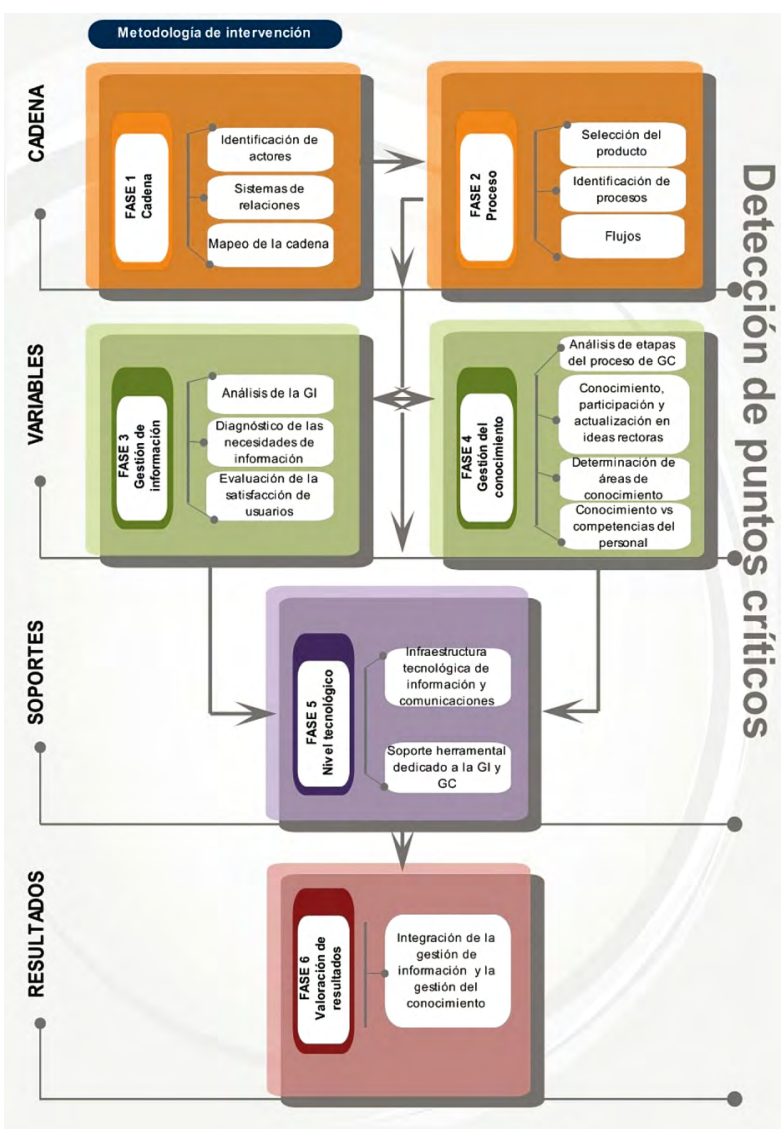

Fuente: Alba, 2020, p. 76.
2.1.3 Métodos de recogida, almacenamiento, procesamiento, análisis y comunicación de datos

Para la recolección de información se selecciona un paquete herramental compuesto por: entrevista personal, cuestionario, observación directa, criterio de expertos, análisis documental, los que se articulan en las diferentes variables de estudio para dar solidez científica a los resultados obtenidos. Para la validación de los datos se trabaja con el software SPSS, mientras que para la integración de los resultados cualitativos se aplica la técnica Ishikawa.

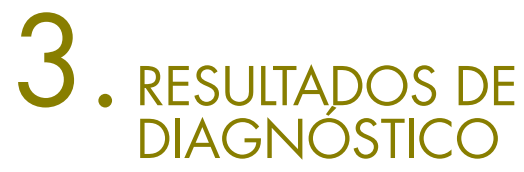

\subsection{ANÁLISIS Y REFLEXIÓN}

Atendiendo a que las etapas 1 y 2 se desarrollaron previamente para la presentación del caso, se comienza en esta sección por la etapa 3 de la metodología de diagnóstico, la cual permite conocer las necesidades de información dentro del proceso de producción del aguardiente. Para ello se aplicaron las técnicas: entrevista personal (anexo 2) y observación directa. La tabulación de estas técnicas permitió la construcción de la figura 7 .

Figura 7. Necesidades de información en la producción de aguardiente.

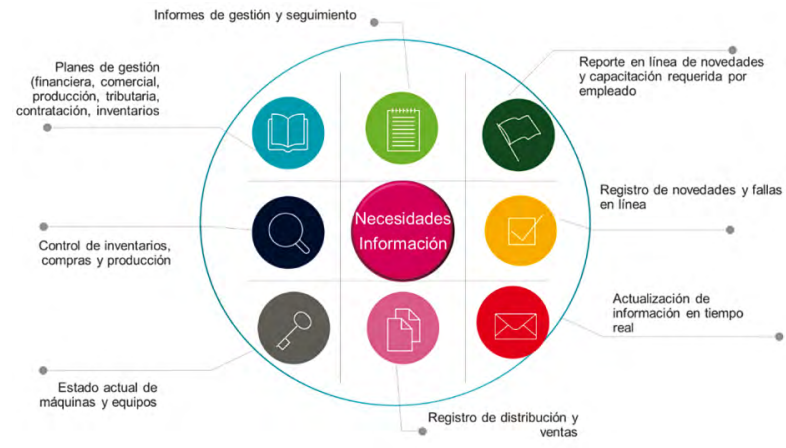

Fuente: Elaboración propia 
Para evaluar el nivel de satisfacción de los usuarios que intervienen en el proceso de producción del aguardiente se aplicó la técnica de entrevista personal (anexo 2), a través de la cual se llega a los siguientes resultados:

- La compañía responsable del proceso productivo adquirió un sistema robusto de información (SAP), el cual es un Enterprise Resource Planning (ERP) que dentro de su concepción no tiene las capacidades técnicas para gestionar el conocimiento.

- Las comunicaciones entre las áreas que conforman el proceso productivo se realizan con poca formalidad y solo se utiliza el sistema Orfeo (sistema de correspondencia), sin tener en cuenta que esta herramienta puede utilizarse para fines complementarios a la gestión de la información.

- Actualmente no se cuenta con un manual de procedimientos por seguir en los procesos entre áreas ni las plantillas por utilizar.

- Debido a la carencia u omisión en el funcionamiento de los sistemas de información actuales, los colaboradores llevan consigo registros manuales y/o herramientas archivadas en equipos propios sin tener aplicativos donde se comparta la información de interés.

- No existe un sistema interactivo que permita evaluar las bajas en la producción, lo que impide un control eficaz para la auditoría de los insumos y las materias primas.

- De manera unánime los entrevistados consideran que la comunicación en la entidad no es efectiva, ya que existe demora en la entrega de la información.

Para el análisis de etapas del proceso de gestión del conocimiento, se aplican las técnicas del cuestionario (anexo 3) y la entrevista personal (anexo 2) a los directivos principales de las subgerencias y oficinas asesoras. El procesamiento del cuestionario se realiza mediante el software SPSS con el empleo de diagramas de cajas, Figura 8 y 9, los cuales permitieron evidenciar que:
Dentro del nivel de importancia en el proceso de producción de aguardiente, de acuerdo con la Figura 8, la adquisición se ubica entre 3 y 5 , siendo una de las más relevantes. En cuanto al almacenamiento, se sitúa entre los valores 3 y 4, presentando una dispersión similar a la adquisición. La transferencia se sitúa entre 1 y 4. Para finalizar, se detecta la creación de conocimiento con una dispersión entre 2 y 3 , con un caso atípico evaluado con calificación de 5, lo que indica que es el proceso al cual se le brinda la menor importancia dentro del proceso de producción.

Los resultados provenientes de la figura 8 indican que el proceso de producción de aguardiente fija su importancia en la adquisición y uso del conocimiento como consecuencia de la experiencia e instrucción adquirida, poniéndola al servicio del proceso de producción y de esta manera, generar los mejores resultados.

Figura 8. Criterios de gestión del conocimiento por nivel de importancia.

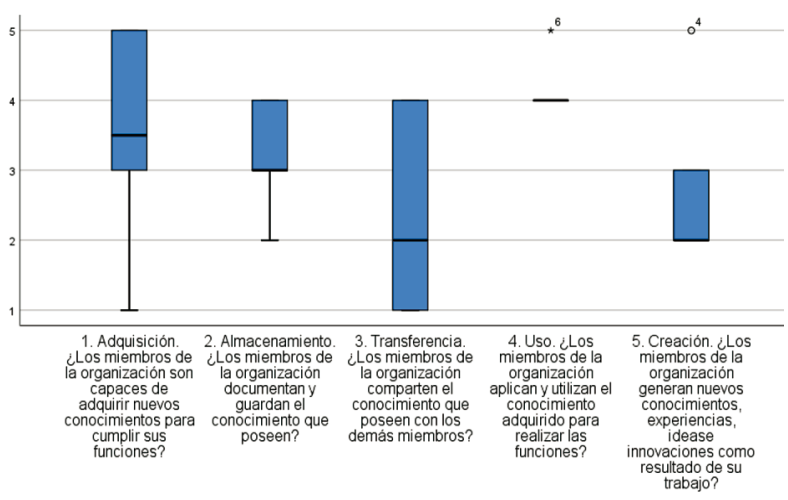

Fuente: Elaboración propia.

A partir de la figura 9 se detecta que la adquisición es un proceso calificado con alta frecuencia (entre 2 y 3); el almacenamiento exhibe una frecuencia similar al de la adquisición, lo que indica que estos dos procesos se utilizan conjuntamente (alta frecuencia). A diferencia de estos, la transferencia de conocimiento tiene baja frecuencia, la cual maneja un rango de 1 a 2 . El uso del conocimiento es de alta frecuencia para el proceso productivo 
Los resultados fueron agrupados en cuatro espinas (sistema, método, personas y finanzas); se evidencia que existe una espina con mayor cantidad de insatisfacciones, asociadas directamente a temas informacionales; por ello, teniendo en cuenta esta espina y para la aplicación del método causa-efecto, se considera como efecto final la no gestión del conocimiento en la producción de aguardiente. con características similares a la adquisición y almacenamiento. Finalmente, la creación se ubica en los niveles más bajos.

Al analizar cada una de las categorías del proceso de gestión del conocimiento, adquisición, almacenamiento y uso tienen exactamente la misma frecuencia, lo que permite inferir que, dentro del proceso de producción, estos procesos se utilizan conjunta y sistemáticamente en la interrelación entre cada uno de los actores. En contravía a estos procesos, la transferencia y creación de conocimiento tienen la misma frecuencia (baja); ello indica que no se podrá utilizar todo el conocimiento circulante, por presentarse islas o acumulación de conocimiento. En caso de la baja frecuencia con que se realiza la creación de conocimiento se infiere que se realiza poco la innovación, lo cual para un sector productivo es de vital necesidad.

Figura 9. Criterios de gestión del conocimiento por nivel de frecuencia.

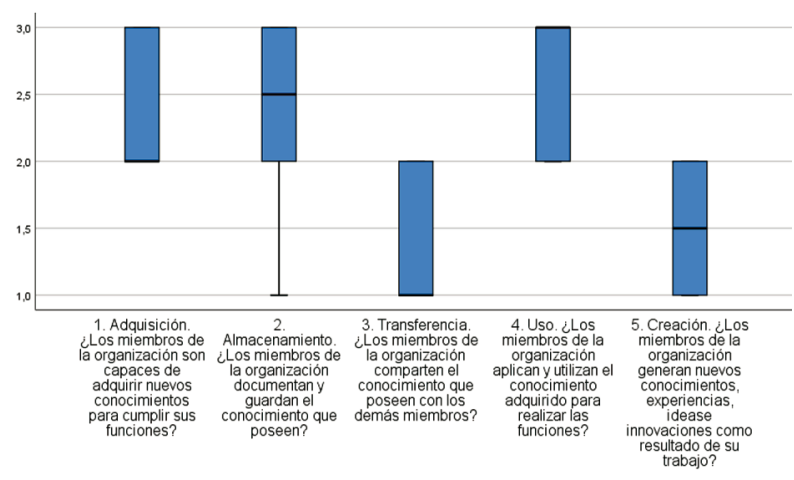

Fuente: Elaboración propia.

\section{DISCUSIÓN}

Teniendo en cuenta la totalización de los resultados mostrados en el diagnóstico, se determina aplicar el método de integración Ishikawa, el cual permite conocer las causas que están provocando el efecto en la producción de aguardiente. Los resultados fueron agrupados en cuatro espinas (sistema, 
método, personas y finanzas); se evidencia que existe una espina con mayor cantidad de insatisfacciones, asociadas directamente a temas informacionales; por ello, teniendo en cuenta esta espina y para la aplicación del método causa-efecto, se considera como efecto final la no gestión del conocimiento en la producción de aguardiente.

Para la aplicación del método Ishikawa se efectuó un proceso de reducción de listado (figura 10); se construye el instrumento de votación y se somete a seis (6) expertos.

Se comprueba que la espina que asocia las principales causas de la no gestión del conocimiento es la de "métodos", la cual muestra que al no existir procedimientos que permitan priorizar y clasificar la información en concordancia con las necesidades requeridas, impiden tomar decisiones en tiempo real, lo que motivó a que los expertos vieran la necesidad de que se generen los procedimientos para implementar canales de comunicación y herramientas de medición que permitan darle importancia al flujo de información que interactúa entre procesos.

La segunda espina considerada en importancia es la de "sistema"; su ponderación describe que debido a la no existencia de una herramienta tecnológica y conceptual que permita integrar los sistemas de información particulares de cada área y que a su vez no contemple la interoperabilidad entre los diferentes sistemas, esto lleve a no contar con información oportuna y confiable para los respectivos índices de gestión requeridos a diario. Seguidamente quedaron la espina de finanzas por la falta de control en el proceso de producción y la espina de personas, por la fuga de conocimiento tácito.

Figura 10. Diagrama causa-efecto en el proceso de producción de aguardiente.

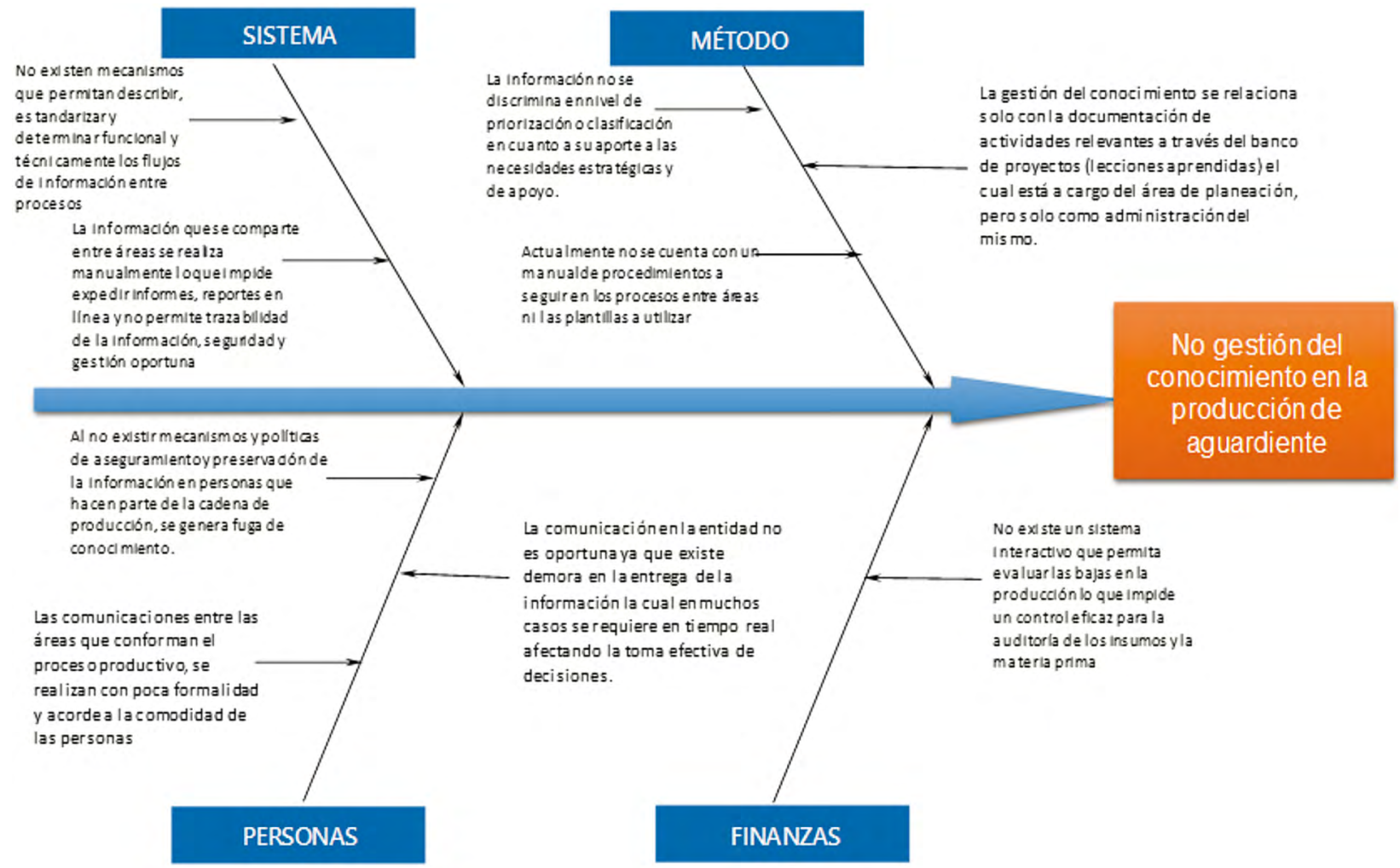

Fuente: Elaboración propia. 
Teniendo las problemáticas comprobadas se procede a evaluar la idea de investigación: el modelo de gestión del infoconocimiento contribuye al uso, transferencia y conservación del conocimiento, reconocimiento de flujos de información, políticas de almacenamiento y difusión en la producción de aguardiente. Para validar esta idea se construye el modelo de infoconocimiento para la producción de aguardiente, en donde se incorpora el sistema de planificación de recursos empresariales (ERP) como una herramienta integradora (figura 11).

El modelo inicia con la identificación de las etapas por las que transita el proceso productivo. De estas etapas se identifican actores, sistemas de relaciones, estructura del proceso productivo a través de un mapa de relaciones, recursos, etapas del producto y actores. Se selecciona el producto y de él se destacan procesos y flujos presentes, los mecanismos de gestión de información y conocimiento, y las tecnologías de información que se emplean. Esta información llega a la espiral del infoconocimiento, donde se encuentran identificados los elementos que desde la gestión de información y conocimiento han de ser gestionados.

El éxito del infoconocimiento se basa en la incorporación de herramientas informáticas, las que interactúan bajo la concepción de un ERP, aspecto novedoso aportado en esta investigación para la teoría, lo cual se sustenta en el planteamiento de Sprague (2019), el cual reconoce que los ERP constituyen la infraestructura central de los procesos; sirven de columna vertebral de los procesos de un sistema más amplio de arquitectura. En cualquier caso, la inversión en sistemas ERP es significativa para las empresas, pero debería proporcionar un alto retorno de la inversión en la mejora de los resultados empresariales. En este caso se aprovecha la existencia de esta herramienta en la producción de aguardiente para incluir funcionalidades desde la concepción del infoconocimiento, ellas son: las notificaciones, los

Figura 11. Modelo de infoconocimiento para la producción de aguardiente.

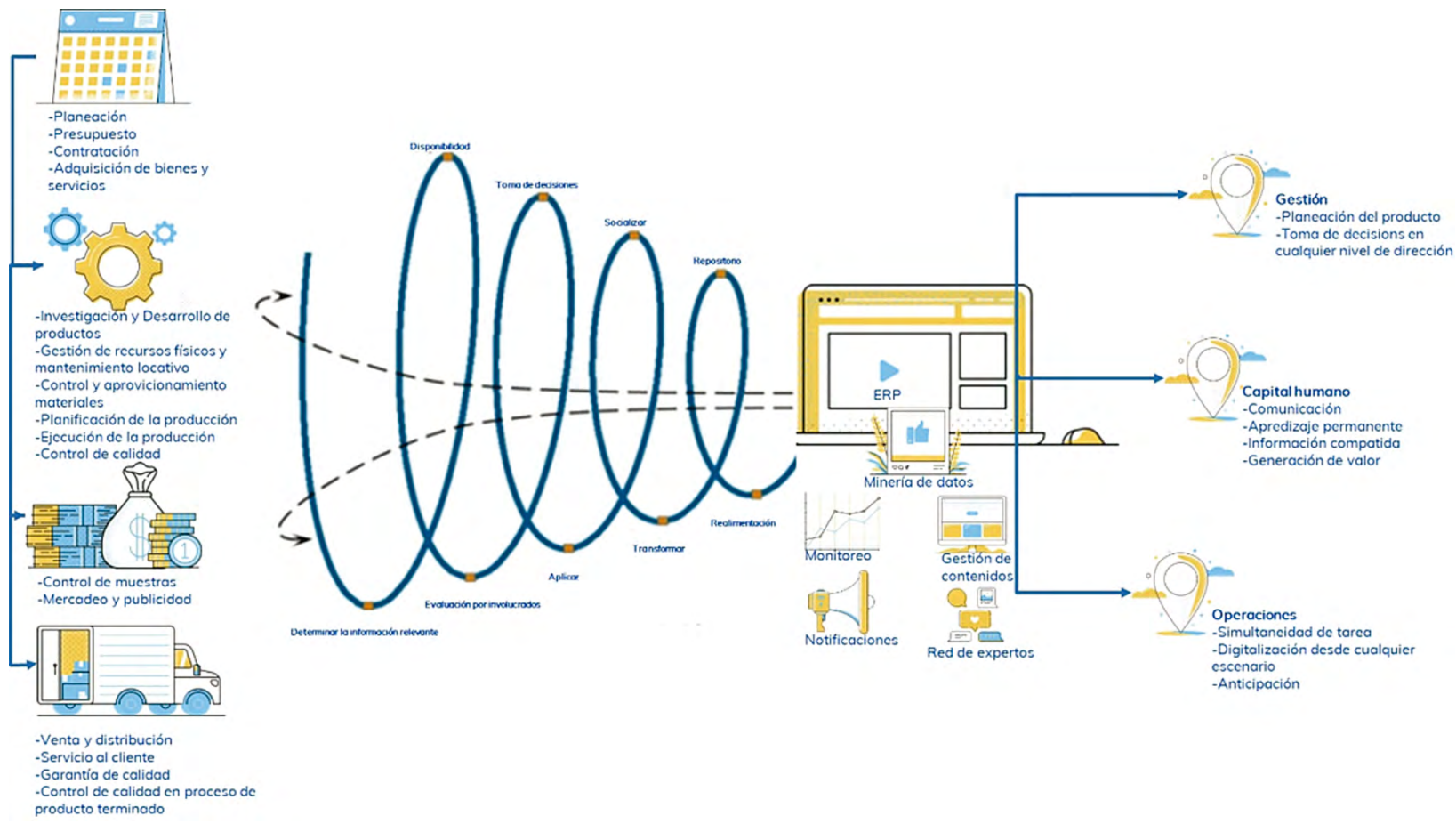

Fuente: adaptado de Alba (2020). 
reportes e informes, los cuales funcionan a través de la gestión de contenidos, la monitorización del proceso, las notificaciones, la minería de datos y la red de expertos (figura 5).

Esta concepción de infoconocimiento impacta en tres áreas fundamentales: la gestión, el capital humano y las operaciones clave del proceso productivo. Esta modelación teórica establece dos retroalimentaciones: una de mantenimiento del proceso productivo y otra de mantenimiento de las herramientas tecnológicas.

- ¿Cómo el infoconocimiento responde al uso, transferencia y conservación del conocimiento y reconocimiento de flujos de información? El bloque de notificaciones contribuirá a mantener el proceso comunicativo constante y sentar las bases primarias de la comunicación interna, por lo cual se encargará de los avisos, alarmas y mensajes que llegan a los escenarios de cada directivo o especialista indicándoles fechas de vencimiento, actualizaciones, nuevas informaciones, nuevas asignaciones de trabajo y un conjunto de acciones que son configurables de acuerdo con las exigencias de la dirección, como son avisos - mensajes de reconocimiento, retrasos e incumplimientos. Estas notificaciones se soportarán en la monitorización permanente que ofrece el ERP. Este espacio también permitirá la participación de expertos, los cuales ante las notificaciones interactuarán, promoviendo la reflexión y el intercambio de conocimiento en la red.

- ¿Cómo responde el infoconocimiento a la creación de políticas de almacenamiento y difusión en la producción de aguardiente? Las políticas de almacenamiento quedan estandarizadas a partir de las herramientas como la minería de datos, la cual filtra la información de diferentes maneras a partir de informes prediseñados para facilitar la toma de decisiones, cuenta con las bases de datos contenidas en ERP. Seguidamente se logra la gestión de contenidos, lo cual permite

\section{El éxito del infoconocimiento} se basa en la incorporación de herramientas informáticas, las que interactúan bajo la concepción de un ERP, aspecto novedoso aportado en esta investigación para la teoría, ..., el cual reconoce que los ERP constituyen la infraestructura central de los procesos; sirven de columna vertebral de los procesos de un sistema más amplio de arquitectura. 
el acceso y el tratamiento a los recursos de información, incluye el tratamiento de los registros y archivos, las herramientas informáticas y los usuarios finales.

Mediante el estudio de caso de la producción de aguardiente se comprueba la flexibilidad del modelo de infoconocimiento para adaptarse a otros procesos productivos, la integralidad de sus herramientas para asegurar la resolución de problemas desde una única plataforma, el asegurar que todas las demandas de información y conocimiento que presenta este proceso estén resueltas desde la incorporación del modelo, se garantiza el tratamiento de la información y el conocimiento en tiempo real, a la vez que crea las bases para la integración de la comunicación y los flujos de infoconocimiento en este proceso. Asimismo, se incorpora por primera vez en esta teoría la herramienta ERP.

\section{CONCLUSIONES}

1) El diagnóstico realizado a la producción de aguardiente permite identificar que existe fuga de conocimiento por la existencia de procesos sin estandarización, flujos de información que tienen el inicio en un área pero que no interactúan con los demás procesos $y$, por ende, la cadena de información se rompe abruptamente; desconocimiento de las herramientas informáticas existentes, ocasionando pérdida de conocimiento al no centralizar la totalidad de la información y el conocimiento.

2) La revisión de modelos de gestión del conocimiento y sus soportes permitió identificar la teoría de infoconocimiento como propuesta de solución a la problemática de la producción de aguardiente. Asimismo, se comprueba la flexibilidad del modelo de infoconocimiento para adaptarse a otros procesos productivos, la integralidad de sus herramientas para asegurar la resolución de problemas, así como todas las demandas de información y conocimiento. Como aspecto novedoso de esta investigación, se incorpora una nueva herramienta tecnológica en la teoría de infoconocimiento.

\section{REFERENCIAS}

Alba, M., \& Herrera, K. (2013). La Gestión del Conocimiento (GC): conceptos, modelos, procesos y experiencias en Cuba. Investigaciones Doctorales en las Ciencias Administrativas y Contables, 199.

Alba, Marisleidy (2020). El Infoconocimiento: una propuesta gerencial. Bogotá D.C.: Univerisdad Externado de Colombia.

Alba, Marisleidy, \& Herrera, K. (2016). Modelo de gestión del infoconocimiento para cadenas de suministro de ron a granel. Cofin Habana, 10(1), 28-38.

Andersen, A. (1999). Management en el siglo XXI: Herramientas para los desafios empresariales de la proxima década (Granica). Buenos Aires.

Arias-Pérez, J.; Tavera-Mesias, J., \& Castaño-Serna, D. (2016). Building a knowledge management maturity model for a multinational food company from an emerging economy. Profesional de la Informacion, 25(1), 88-102. https://doi. org/10.3145/epi.2016.ene.09

Arias, J. E., \& Tavera, J. F. (2015). Linking knowledge management maturity and innovation in leading companies in research and development. Revista Republicana, 18, 159-180. http:// ois.urepublicana.edu.co/index.php/ revistarepublicana/article/view/212/173

Briceño Moreno, M., \& Bernal Torres, C. (2010). Estudios de caso sobre la gestión del conocimiento en cuatro organizaciones colombianas líderes en penetración de mercado. Estudios Gerenciales, 26(1 17), 173193.

Cepeda Carrión, G. A. (2006). La calidad en los métodos de investigación cualitativa: principios 
de aplicación práctica para estudios de casos. Cuadernos de Economía y Dirección de la Empresa, (29), 57-82.

Choo, C. W. (1995). Information Management for the Intelligent Organization: Roles and Implications for the Information Professions. Raffles City Convention Centre Singapore, 80-99. http://choo.ischool.utoronto.ca/FIS/ respub/DLC95.pdf

Cuesta Santos, A., \& Valencia Rodríguez, M. (2014). Indicadores de Gestión del Capital Humano y del Conocimiento en la empresa. La Habana.

Dataware Technologies Inc. (1998). Seven Steps to Implementing Knowledge Management in Your Organization. Knowledge Management, 32. http://www.systems-thinking.org/kmgmt/ km7steps.pdf

Denzin, N., \& Lincoln, Y (1994). Handbook of qualitative research. Thousand Oaks, CA: Sage.

Firestone, J. (2001). Methodology: An Overview. Journal of the KMC, 1 (June)

Follador, R., \& Gonzaga, L. (2015). Knowledge Management maturity level in a Brazilian Air Force flight test environment. Portland International Conference on Management of Engineering and Technology, 2015Sept.(August), 1296-1304. https://doi. org/10.1109/PICMET.2015.7272952

Franch, K.; Herrera, K., \& Losada, A. (2011). La Gestión del conocimiento como herramienta de apoyo al proceso de toma de decisiones: Caso de estudio Dirección General TRD Caribe.

González, A.;, Joaquí, C., \& Collazos, C. (2009). Karagabi kmmodel: modelo de referencia para la introducción de iniciativas de gestión del conocimiento en organizaciones basadas en conocimiento. Ingeniare. Revista chilena de ingeniería, 17(2), 223235. https://doi.org/10.4067/s0718$\underline{33052009000200011}$
Hedlund, G. (1994). A Model of Knowledge Management and the N-Form Corporation. Strategic Management Journal, 15, 73-90. https://www.jstor.org/stable/2486877

Kerschberg, L. (2000). Knowlegde management: managing knowlegde resources for the intelligent enterprise.

Kogut, B., \&Zander, U. (1992). Knowledge of the firm, combinative capabilities and the replication of the technology. Organization Science, Vol. 3, 383397. hitps://doi.org/10.1287/orsc.3.3.383

Lincoln, Y. S., \& Guba, E. G. (1985). Establishing trustworthiness. Naturalistic inquiry, 289(331), 289-327.

Nonaka, I., \& Takeuchi, H. (1995). The KnowledgeCreating Company: How Japanese Companies Create the Dynamics (Oxford University). https:// books.google.com.co/books? id=tmziBwAAQB AJ\&printsec $=$ frontcover\&hl=es\&source =gbs_ge summary $r \&$ cad $=0 \# v=$ onepage $\& q \& f=$ false

Okoli, C., \& Schabram, K. (2010). Working Papers on Information Systems A Guide to Conducting a Systematic Literature Review of Information Systems Research. En Working Papers on Information Systems (Vol. 10). https://doi. org/10.2139/ssrn.1954824

Oliveira, M.; Pedron, C.; Romão, M., \& Becker, G. (201 1). Proposta de um modelo de maturidade para Gestão do Conhecimento: KM 3. Revista Portuguesa E Brasileira De Gestão, 10(4), 1 1-25.

Robson, C. (1993). Real Word Research: A Recourse for Social Scientists and PracticionersResearchers, Blackwell, Oxford.

Romero, D., \& Pascual, F. (2011). Análisis De Madurez De La Gestión Del Capital Intelectual En La Pequeña Y Mediana Empresa. Revista Da Micro E Pequena Empresa, 5131, 40-60. https://doi.org/10.6034/229

Salcedo, F., \& Riveros, J. (2020). La gestión del conocimiento en el proceso de producción de Aguardiente. Universidad Externado de Colombia. 
Soto Balbón, M. A. (2005). Modelación de la gestión del conocimiento para las organizaciones cubanas a través de los portales de información (Universidad de La Habana).

Sprague, C. (2019). Enterprise Resource Planning. Salem Press Encyclopedia.

Sveiby, K. E. (1997). The New Organizational Wealth: Managing \& Measuring Knowledgebased Assets. https://books.google.com. co/books? $h|=e s \&| r=\& i d=x K N X \mid$ gaeCiAC\& oi=fnd\&pg $=$ PR9\&dq=Sveiby, + K. $+(1997) \&$ ots $=9 \mathrm{WLliqB8g} \&$ sig $=E w 4 x x+A L s 4 e N 6 z q u$ Fn-7yDdkd-E\#v=onepage\&q=Sveiby\%2C K. 1 1997)\&f=false
Tejedor, B., \& Aguirre, A. (1998). Proyecto logos: investigadores relativa a la capacidad de aprender de las empresas españolas, boletin de estudios econoómicos, 53(154),23 1-249Dialnet. https://dialnet.unirioja.es/servlet/ articulo? codigo $=4784$

Wiig, K. M. (1993). Knowledge management foundations: thinking about thinking: how ..., Volume 1. En Schema Press (Vol. 1). Arlington, Texas.

Yin, R. K. (1981). The case study as a serious research strategy. Knowledge, 3(1), 97-1 14.

Yin, R. K (1984). Case study research. Beverly Hills, CA. Sage. 


\section{ANEXOS}

ANEXO 1. ANÁLISIS DE MODELOS DE GESTIÓN DEL CONOCIMIENTO.

\begin{tabular}{|c|c|c|c|c|c|}
\hline Autor & Año & Orientación en la GC & $\begin{array}{l}\text { Categorías que } \\
\text { involucra }\end{array}$ & Enfoques $^{2}$ & $\begin{array}{c}\text { Soporte } \\
\text { tecnológico }\end{array}$ \\
\hline $\begin{array}{l}\text { Kogut y } \\
\text { Zander }\end{array}$ & 1992 & $\begin{array}{l}\text { El crecimiento a través } \\
\text { del aprendizaje externo } \\
\text { e interno, capacidades } \\
\text { combinativas. }\end{array}$ & $\begin{array}{l}\text { Aprendizaje externo e } \\
\text { interno. Capacidades } \\
\text { combinativas. }\end{array}$ & $\begin{array}{l}\text { Capital } \\
\text { humano. } \\
\text { Competencias }\end{array}$ & No presenta \\
\hline Karl Wiig & 1993 & $\begin{array}{l}\text { Se basa en la } \\
\text { exploración y } \\
\text { adecuación del } \\
\text { conocimiento; } \\
\text { la estimación y } \\
\text { evaluación del valor del } \\
\text { conocimiento y de las } \\
\text { actividades relacionadas } \\
\text { y la actividad dominante } \\
\text { en la GC. }\end{array}$ & $\begin{array}{l}\text { Exploración y } \\
\text { adecuación del } \\
\text { conocimiento. } \\
\text { Estimación y } \\
\text { evaluación del valor } \\
\text { del conocimiento, }\end{array}$ & $\begin{array}{l}\text { Proceso de } \\
\text { gestión del } \\
\text { conocimiento } \\
\text { (GC) }\end{array}$ & No presenta \\
\hline Hedlund & 1994 & $\begin{array}{l}\text { Creación, transformación } \\
\text { y transferencia del } \\
\text { conocimiento en la } \\
\text { empresa, basado en el } \\
\text { modelo propuesto por } \\
\text { Nonaka y Takeuchi. }\end{array}$ & $\begin{array}{l}\text { Creación, } \\
\text { transformación y } \\
\text { transferencia del } \\
\text { conocimiento. }\end{array}$ & Proceso de GC & No presenta \\
\hline $\begin{array}{l}\text { Ikujiro } \\
\text { Nonaka, } \\
\text { Hirotaka } \\
\text { Takeuchi } \\
\text { (Japón) }\end{array}$ & 1995 & $\begin{array}{l}\text { Conocimiento } \\
\text { organizativo a partir de } \\
\text { dos dimensiones: la } \\
\text { epistemológica y la } \\
\text { ontológica. }\end{array}$ & $\begin{array}{l}\text { Conocimiento } \\
\text { organizativo }\end{array}$ & Gerencial & No presenta \\
\hline C. Choo & 1996 & $\begin{array}{l}\text { La organización usa la } \\
\text { información estratégica } \\
\text { para la creación y } \\
\text { entendimiento del } \\
\text { conocimiento y la toma } \\
\text { de decisiones. }\end{array}$ & $\begin{array}{l}\text { Información } \\
\text { estratégica, creación } \\
\text { y entendimiento del } \\
\text { conocimiento. } \\
\text { Toma de decisiones. } \\
\text { Procesar información. } \\
\text { Resolver situaciones. }\end{array}$ & $\begin{array}{l}\text { Proceso de } \\
\text { gestión de } \\
\text { información } \\
\text { (Gl). Proceso de } \\
\text { GC. Gerencial. }\end{array}$ & No presenta \\
\hline $\begin{array}{l}\text { Karl Erick } \\
\text { Sveiby }\end{array}$ & 1997 & $\begin{array}{l}\text { Está centrado en la } \\
\text { importancia de los } \\
\text { activos intangibles. }\end{array}$ & Activos intangibles & $\begin{array}{l}\text { Capital } \\
\text { intelectual }\end{array}$ & No presenta \\
\hline $\begin{array}{l}\text { Tejedor y } \\
\text { Aguirre }\end{array}$ & 1998 & $\begin{array}{l}\text { Factores que } \\
\text { condicionan la } \\
\text { capacidad de } \\
\text { aprendizaje de una } \\
\text { organización, así como } \\
\text { los resultados esperados. }\end{array}$ & $\begin{array}{l}\text { Capacidad de } \\
\text { aprendizaje }\end{array}$ & $\begin{array}{l}\text { Competencias. } \\
\text { Capital humano }\end{array}$ & No presenta \\
\hline
\end{tabular}

2 Esta concepción de enfoques responde a la clasificación de Alba \& Herrera (2013). 


\begin{tabular}{|c|c|c|c|c|c|}
\hline Autor & Año & Orientación en la GC & $\begin{array}{l}\text { Categorías que } \\
\text { involucra }\end{array}$ & Enfoques $^{2}$ & $\begin{array}{c}\text { Soporte } \\
\text { tecnológico }\end{array}$ \\
\hline $\begin{array}{l}\text { Dataware } \\
\text { Technologies } \\
\text { Inc., (1998) }\end{array}$ & 1998 & $\begin{array}{l}\text { Identificación del } \\
\text { problema de negocio, } \\
\text { preparar el negocio } \\
\text { para el cambio, crear } \\
\text { equipo de trabajo, } \\
\text { ejecutar auditorías de } \\
\text { conocimiento, definir } \\
\text { características asociadas } \\
\text { a tecnología, construir } \\
\text { soluciones por bloques y } \\
\text { enlazar el conocimiento } \\
\text { con la gente. }\end{array}$ & $\begin{array}{l}\text { Identificar y preparar } \\
\text { problema de negocio. } \\
\text { Crear equipo de } \\
\text { trabajo. } \\
\text { Auditorías de } \\
\text { conocimiento. } \\
\text { Tecnologías. } \\
\text { Soluciones por } \\
\text { bloques. } \\
\text { Enlazar conocimiento } \\
\text {-gente }\end{array}$ & $\begin{array}{l}\text { Gerencial. } \\
\text { Competencias. } \\
\text { Gestión } \\
\text { tecnológica. }\end{array}$ & $\begin{array}{l}\text { Se basa en } \\
\text { gestión de } \\
\text { información, } \\
\text { incorpora } \\
\text { algunas } \\
\text { funciones de } \\
\text { la gestión del } \\
\text { conoci-miento }\end{array}$ \\
\hline $\begin{array}{l}\text { Arthur } \\
\text { Andersen y } \\
\text { APQC }\end{array}$ & 1999 & $\begin{array}{l}\text { Instrumento que propone } \\
\text { cuatro facilitadores } \\
\text { para administrar } \\
\text { el conocimiento } \\
\text { organizacional. } \\
\text { Identifica las brechas de } \\
\text { conocimiento. }\end{array}$ & $\begin{array}{l}\text { Administrar el } \\
\text { conocimiento. Brechas } \\
\text { de conocimiento. }\end{array}$ & Proceso de GC & No presenta \\
\hline Kerschberg & 2000 & $\begin{array}{l}\text { Modelo de la } \\
\text { integración tecnológica, } \\
\text { heterogeneidad de las } \\
\text { fuentes de conocimiento; } \\
\text { establece componentes } \\
\text { que se } \\
\text { integran. }\end{array}$ & $\begin{array}{l}\text { Integración } \\
\text { tecnológica. } \\
\text { Heterogeneidad } \\
\text { de las fuentes de } \\
\text { conocimiento. }\end{array}$ & $\begin{array}{l}\text { Gestión } \\
\text { tecnológica. } \\
\text { Proceso de GC. }\end{array}$ & $\begin{array}{l}\text { No existe } \\
\text { articulación de } \\
\text { información y el } \\
\text { conoci-miento. }\end{array}$ \\
\hline $\begin{array}{l}\text { María A. Soto } \\
\text { Balbón }\end{array}$ & 2005 & $\begin{array}{l}\text { Define los procesos } \\
\text { para el desarrollo de } \\
\text { proyectos. Los procesos } \\
\text { son: diagnóstico, } \\
\text { diseño, implementación } \\
\text { y evaluación para } \\
\text { expresar y evaluar la } \\
\text { GC organizacional. } \\
\text { Incorpora la gestión } \\
\text { de la información, los } \\
\text { soportes } \\
\text { tecnológicos y el capital } \\
\text { humano. }\end{array}$ & $\begin{array}{l}\text { Evaluación de gestión } \\
\text { del conocimiento. } \\
\text { Gestión de la } \\
\text { información. Soportes } \\
\text { tecnológicos. Procesos } \\
\mathrm{CH}\end{array}$ & $\begin{array}{l}\text { Proceso de GC. } \\
\text { Proceso de Gl. } \\
\text { Gestión } \\
\text { tecnológica. } \\
\text { Gerencial. } \\
\text { Capital humano. }\end{array}$ & $\begin{array}{l}\text { Se basa en } \\
\text { gestión de } \\
\text { información. } \\
\text { Funcio-nalidades } \\
\text { reactivas. }\end{array}$ \\
\hline $\begin{array}{l}\text { González, } \\
\text { Joaquí \& } \\
\text { Collazos }\end{array}$ & 2009 & $\begin{array}{l}\text { Modelo Karagabi } \\
\text { KM Model. Guía } \\
\text { de referencia para } \\
\text { la construcción de } \\
\text { organizaciones } \\
\text { orientadas al } \\
\text { conocimiento. El modelo } \\
\text { propone: metodología } \\
\text { de intervención, } \\
\text { librería de modelos de } \\
\text { conocimiento y base } \\
\text { de conocimiento de } \\
\text { experiencias. }\end{array}$ & $\begin{array}{l}\text { Guía de referencia. } \\
\text { Construcción de } \\
\text { organizaciones. } \\
\text { Metodología de } \\
\text { intervención. } \\
\text { Modelos } \\
\text { Experiencias }\end{array}$ & $\begin{array}{l}\text { Capital } \\
\text { intelectual. } \\
\text { Gerencial. } \\
\text { Capital } \\
\text { humano. }\end{array}$ & No presenta \\
\hline
\end{tabular}




\begin{tabular}{|c|c|c|c|c|c|}
\hline Autor & Año & Orientación en la GC & $\begin{array}{l}\text { Categorías que } \\
\text { involucra }\end{array}$ & Enfoques $^{2}$ & $\begin{array}{c}\text { Soporte } \\
\text { tecnológico }\end{array}$ \\
\hline $\begin{array}{l}\text { Briceño \& } \\
\text { Bernal }\end{array}$ & 2010 & $\begin{array}{l}\text { Caso de estudio que } \\
\text { evidencia coincidencias } \\
\text { entre concepto y } \\
\text { enfoque que tienen } \\
\text { las organizaciones } \\
\text { sobre GC y a su vez } \\
\text { el contraste en la } \\
\text { importancia que dan las } \\
\text { organizaciones a las } \\
\text { variables que componen } \\
\text { dicha gestió. }\end{array}$ & $\begin{array}{l}\text { Caso de estudio. } \\
\text { Concepto } \\
\text { Enfoque } \\
\text { Variables } \\
\text { Gestión }\end{array}$ & $\begin{array}{l}\text { Capital } \\
\text { intelectual }\end{array}$ & No presenta \\
\hline Katia Franch & 2011 & $\begin{array}{l}\text { Conjunto de indicadores } \\
\text { para la gestión del } \\
\text { conocimiento en la toma } \\
\text { de decisiones. }\end{array}$ & $\begin{array}{l}\text { Gestión del } \\
\text { conocimiento. Toma } \\
\text { de decisiones. }\end{array}$ & $\begin{array}{l}\text { Proceso de GC } \\
\text { Gerencial }\end{array}$ & No presenta \\
\hline $\begin{array}{l}\text { Oliveira, } \\
\text { Pedron, } \\
\text { Romao \& } \\
\text { Becker }\end{array}$ & 2011 & $\begin{array}{l}\text { Modelo KM3: Este } \\
\text { modelo consta de cinco } \\
\text { etapas: Falta conciencia } \\
\text { (2 factores), Planificación } \\
\text { (15 factores), Iniciación } \\
\text { (20 factores), Desarrollo } \\
\text { (24 factores) y la } \\
\text { integración (24 factores). } \\
\text { Además establece tres } \\
\text { (3) áreas clave: cultura } \\
\text { organizacional, soporte } \\
\text { de alta administración } \\
\text { y estructura } \\
\text { organizacional. }\end{array}$ & $\begin{array}{l}\text { Conciencia } \\
\text { Planificación } \\
\text { Iniciación } \\
\text { Desarrollo } \\
\text { Integración } \\
\text { Cultura organizacional } \\
\text { Soporte } \\
\text { Alta administración } \\
\text { Estructura } \\
\text { organizacional }\end{array}$ & $\begin{array}{l}\text { Gerencial } \\
\text { Competencias } \\
\text { Capital } \\
\text { intelectual } \\
\text { Capital humano } \\
\text { Competencias }\end{array}$ & No presenta \\
\hline $\begin{array}{l}\text { Romero \& } \\
\text { Pascual }\end{array}$ & 2011 & $\begin{array}{l}\text { Modelo exploratorio } \\
\text { que se basa en una } \\
\text { relación causa - efecto, } \\
\text { que a su vez resulta } \\
\text { de la vinculación entre } \\
\text { las TI/SI (planificación } \\
\text { estratégica), la cultura y } \\
\text { el capital humano con la } \\
\text { GC en el marco de un } \\
\text { modelo de madurez. }\end{array}$ & $\begin{array}{l}\text { Exploratorio } \\
\text { Causa-efecto } \\
\text { Planificación } \\
\text { estratégica } \\
\text { Cultura } \\
\text { Capital humano } \\
\text { Madurez } \\
\text { SI } \\
\text { TI }\end{array}$ & $\begin{array}{l}\text { Proceso de Gl } \\
\text { Proceso de GC } \\
\text { Gestión } \\
\text { tecnológica } \\
\text { Gerencial } \\
\text { Competencias } \\
\text { Capital humano } \\
\text { Capital } \\
\text { intelectual }\end{array}$ & $\begin{array}{l}\text { No existe } \\
\text { articulación de } \\
\text { información y el } \\
\text { conocimiento. } \\
\text { Los procesos } \\
\text { se dan por } \\
\text { separado }\end{array}$ \\
\hline $\begin{array}{l}\text { Marisleidy } \\
\text { Alba }\end{array}$ & 2013 & $\begin{array}{l}\text { Indicadores para } \\
\text { integrar gestión de } \\
\text { información y gestión del } \\
\text { conocimiento a través de } \\
\text { un soporte tecnológico } \\
\text { donde } \\
\text { participa el capital } \\
\text { humano. }\end{array}$ & $\begin{array}{l}\text { Gestión de } \\
\text { información. Gestión } \\
\text { del conocimiento. } \\
\text { Soporte tecnológico. } \\
\text { Capital humano. }\end{array}$ & $\begin{array}{l}\text { Proceso de Gl. } \\
\text { Proceso de GC. } \\
\text { Gestión } \\
\text { tecnológica. } \\
\text { Capital } \\
\text { humano. }\end{array}$ & $\begin{array}{l}\text { El soporte } \\
\text { no articula } \\
\text { de manera } \\
\text { integral Gl y } \\
\text { GC. Desarrolla } \\
\text { solo algunas } \\
\text { funciones } \\
\text { aisladas. }\end{array}$ \\
\hline
\end{tabular}




\begin{tabular}{|c|c|c|c|c|c|}
\hline Autor & Año & Orientación en la GC & $\begin{array}{l}\text { Categorías que } \\
\text { involucra }\end{array}$ & Enfoques $^{2}$ & $\begin{array}{c}\text { Soporte } \\
\text { tecnológico }\end{array}$ \\
\hline Follador & 2015 & $\begin{array}{l}\text { La GC en un entorno de } \\
\text { prueba de vuelo de la } \\
\text { Fuerza Aérea Brasileña } \\
\text { se vio afectada por el } \\
\text { establecimiento de una } \\
\text { estructura de gestión de } \\
\text { la ciencia y tecnología. } \\
\text { La metodología } \\
\text { propuesta por el autor } \\
\text { para la medición del } \\
\text { nivel de madurez de GC } \\
\text { constaba de } 3 \text { niveles: } \\
\text { avanzado, intermedio } \\
\text { e inicial; además } \\
\text { estableció las áreas } \\
\text { clave de personas, } \\
\text { cultura, procesos y } \\
\text { tecnología. }\end{array}$ & $\begin{array}{l}\text { Ciencia y tecnología. } \\
\text { Cultura } \\
\text { Procesos } \\
\text { Personas }\end{array}$ & $\begin{array}{l}\text { Proceso de GC. } \\
\text { Competencias. } \\
\text { Gestión } \\
\text { tecnológica. } \\
\text { Capital } \\
\text { humano. }\end{array}$ & $\begin{array}{l}\text { No existe } \\
\text { articulación de } \\
\text { información y el } \\
\text { conocimiento. } \\
\text { Desarrolla } \\
\text { solo algunas } \\
\text { funciones } \\
\text { aisladas. }\end{array}$ \\
\hline Arias \& Tavera & 2015 & $\begin{array}{l}\text { Exploración de la } \\
\text { relación entre la } \\
\text { madurez de GC y } \\
\text { las innovaciones de } \\
\text { producto y marketing en } \\
\text { empresas líderes en I+D. }\end{array}$ & $\begin{array}{l}\text { Gestión de } \\
\text { conocimiento. } \\
\text { Innovación } \\
\text { Marketing } \\
\text { I+D. }\end{array}$ & $\begin{array}{l}\text { Proceso de GC } \\
\text { Gerencial } \\
\text { Capital } \\
\text { intelectual } \\
\text { Gestión } \\
\text { tecnológica }\end{array}$ & $\begin{array}{l}\text { No existe } \\
\text { articulación de } \\
\text { información y el } \\
\text { conocimiento }\end{array}$ \\
\hline $\begin{array}{l}\text { Alba, } \\
\text { Marisleidy } \\
\text { Herrera, Katy }\end{array}$ & 2016 & $\begin{array}{l}\text { Integración de la } \\
\text { información y el } \\
\text { conocimiento en } \\
\text { una espiral de } \\
\text { infoconocimiento que } \\
\text { facilita la integración } \\
\text { de estos enfoques a } \\
\text { la toma de decisión, } \\
\text { la comunicación, } \\
\text { colaboración y la } \\
\text { planificación. }\end{array}$ & $\begin{array}{l}\text { Gestión de } \\
\text { información, gestión } \\
\text { del conocimiento, } \\
\text { tecnologías de } \\
\text { información, } \\
\text { integración de } \\
\text { procesos productivos. }\end{array}$ & $\begin{array}{l}\text { Capital humano } \\
\text { Competencias } \\
\text { Gerencial } \\
\text { Proceso de GC } \\
\text { Proceso de Gl } \\
\text { Proceso } \\
\text { de gestión } \\
\text { tecnológica. }\end{array}$ & $\begin{array}{l}\text { Integra en un } \\
\text { solo ciclo la } \\
\text { Gl y la GC. } \\
\text { Funcionalidades } \\
\text { activas de } \\
\text { gestión } \\
\text { impactando en } \\
\text { ambos procesos } \\
\text { de Gl y GC. }\end{array}$ \\
\hline $\begin{array}{l}\text { Arias -Pérez } \\
\text { et al. }\end{array}$ & 2016 & $\begin{array}{l}\text { El modelo creado por } \\
\text { los autores estableció } \\
\text { cuatro áreas clave: } \\
\text { estrategia, cultura, } \\
\text { procesos y tecnología, } \\
\text { y una escala de cinco } \\
\text { niveles de madurez: 1) } \\
\text { inicial, 2) exploratorio, } \\
\text { 3) usado, 4l gestionado } \\
\text { e 5) innovación. }\end{array}$ & $\begin{array}{l}\text { Estrategia } \\
\text { Cultura } \\
\text { Procesos } \\
\text { Tecnología } \\
\text { innovación }\end{array}$ & $\begin{array}{l}\text { Gerencial } \\
\text { Proceso de GC. } \\
\text { Gestión } \\
\text { tecnológica. } \\
\text { Capital } \\
\text { humano. } \\
\text { Competencia }\end{array}$ & $\begin{array}{l}\text { No existe } \\
\text { articulación de } \\
\text { información y el } \\
\text { conocimiento. } \\
\text { Funcionalidades } \\
\text { no están } \\
\text { asociadas } \\
\text { a todas las } \\
\text { demandas de Gl } \\
\text { y GC. }\end{array}$ \\
\hline
\end{tabular}

Fuente: elaboración propia. 


\section{ANEXO 2. GUIAA DE ENTREVISTAS PARA APLICAR A DIRECTIVOS Y ESPECIALISTAS IMPLICADOS EN EL DESARROLLO DE PRODUCTOS}

1. ¿Cuáles procesos se llevan a cabo en el desarrollo del producto?

2. ¿Qué actores principales están presentes en el desarrollo del producto?

3. ¿Cómo es el sistema de relaciones que se establece entre los actores principales del producto?

4. Puede mencionar los puntos críticos en el desarrollo del producto?

5. ¿Conoce usted las ideas rectoras de la entidad?

6. ¿̇En qué medida conoce la misión?

7. ¿En qué medida conoce la visión?

8. ¿̇En qué medida conoce la misión?

9. ¿En qué medida conoce los objetivos estratégicos?

10. ¿ Se siente usted implicado en el cumplimiento de las ideas rectoras?

11. ¿De qué tecnologías dispone para desempeñar su trabajo? ¿Cumple con los requerimientos necesarios para manejar y almacenar información?

12. ¿Cómo evalúa el acceso, localización, distribución y socialización de la información?

13. ¿Qué información necesita para efectuar su trabajo?

14. ¿Con cuáles usuarios intercambia información?

15. ¿ Se ha realizado algún estudio de necesidades de información?

16. ¿Se siente capacitado para desempeñar sus funciones? Mencione cinco conocimientos que posee.

17. ¿Qué conocimiento necesita para desempeñarse plenamente en sus funciones?

18. ¿Existe alguna herramienta, aplicación o sistema de información para desempeñar su trabajo?

19. ¿Dispone de acceso a la intranet corporativa, a internet, correo electrónico?

20. ¿Con que grupos o áreas intercambia información?

21. Para este intercambio de información existe algún documento que regule, cómo debe ser el intercambio?

22. ¿Cuáles son las principales hojas de trabajo, documentos, plantillas, procedimientos existentes?

23. ¿Qué vía de comunicación utiliza para intercambiar información con los actores implicados en el desarrollo del producto?

24. ¿Cómo considera esa comunicación? Efectiva o no. En caso negativo, justifique su respuesta.

25. Especifique dentro de la tecnología de información de la que dispone, cómo y para qué se emplean.

26. ¿Cómo es la infraestructura tecnológica y de comunicación en la entidad? ¿Se encuentra distribuida en función de las necesidades?

27. ¿En qué estado técnico se encuentra? ¿Qué nivel de prestaciones presenta?

28. ¿Qué servicios de información prefiere para recuperar la información?

29. ¿Dispone de un sitio web dentro de la intranet corporativa?

Fuente: Alba, 2020. 


\section{ANEXO 3. CUESTIONARIO DE VALORACIÓN DE LOS CRITERIOS DE GESTIÓN DEL CONOCIMIENTO Y SU FRECUENCIA}

Estimado directivo,

Con vistas a conocer cómo es el proceso de gestión del conocimiento en su organización, se le pide su evaluación sobre los criterios que se adjuntan.

\begin{tabular}{|c|c|c|}
\hline Criterios de gestión del conocimiento & $\begin{array}{c}\text { Importancia del criterio }{ }^{3} \\
1-5\end{array}$ & $\begin{array}{l}\text { Frecuencia con que } \\
\text { se hace } \\
0123\end{array}$ \\
\hline $\begin{array}{l}\text { 1. Adquisición. ¿̇Los miembros de la } \\
\text { organización son capaces de adquirir nuevos } \\
\text { conocimientos para cumplir sus funciones? }\end{array}$ & & \\
\hline $\begin{array}{l}\text { 2. Almacenamiento. ¿Los miembros de la } \\
\text { organización documentan y guardan el } \\
\text { conocimiento que poseen? }\end{array}$ & & \\
\hline $\begin{array}{l}\text { 3. Transferencia. ¿Los miembros de la } \\
\text { organización comparten con los demás miembros } \\
\text { el conocimiento que poseen? }\end{array}$ & & \\
\hline $\begin{array}{l}\text { 4. Uso. ¿̇los miembros de la organización } \\
\text { aplican y utilizan el conocimiento adquirido para } \\
\text { realizar las funciones? }\end{array}$ & & \\
\hline $\begin{array}{l}\text { 5. Creación. ¿̀los miembros de la organización } \\
\text { generan nuevos conocimientos, experiencias, } \\
\text { ideas e innovaciones como resultado de su } \\
\text { trabajo? }\end{array}$ & & \\
\hline
\end{tabular}

6. ¿̇En qué momento la información y/o el conocimiento no han estado presentes en la actividad que usted dirige y que haya ocasionado problemas?

7. ¿Qué impacto económico ha generado?

Fuente: Cuesta Santos \& Valencia Rodríguez (2014).

3 Indica el grado de importancia que tiene cada criterio estratégico para los responsables de la organización, considerando que 1 representa el valor más bajo y 5 representa el valor más alto y no puede haber criterios con el mismo valor de importancia.

4 Frecuencia con la que se hace (0 l 123 ) representa (ninguna, poca, frecuente, mucho). 